\title{
ASPECTOS ECOLÓGICOS DA AROEIRA (Myracrodruon urundeuva ALLEMÃO - ANACARDIACEAE): FENOLOGIA E GERMINAÇÃO DE SEMENTES ${ }^{1}$
}

\author{
Yule Roberta Ferreira Nunes², Marcílio Fagundes², Hisaias de Souza Almeida ${ }^{3}$ e Maria das Dores \\ Magalhães Veloso 2,3
}

\begin{abstract}
RESUMO - Myracrodruon urundeuva Allemão, espécie arbórea conhecida como aroeira, constitui-se em um importante componente das Florestas Estacionais Deciduais do norte de Minas Gerais. Apesar disso, a aroeira vem sofrendo um processo de exploração intensa, de forma predatória, o que vem causando a devastação de suas populações naturais. Este trabalho teve como objetivo conhecer os padrões fenológicos reprodutivos e vegetativos, bem como a capacidade germinativa da aroeira, na Área de Preservação da COPASA em Juramento, MG. Foram feitas observações fenológicas quinzenais, no período de janeiro/2002 a novembro/2003, de 20 indivíduos arbóreos, sendo ainda coletadas sementes, submetidas a diferentes tratamentos de escarificação tegumentar (mecânico, térmico, químico e controle). A espécie apresentou as fenofases reprodutivas e vegetativas influenciadas diferencialmente pelas variáveis ambientais de precipitação e temperatura. Na estação seca ocorreram a floração, frutificação e queda foliar, e a estação chuvosa favoreceu o brotamento da espécie. A capacidade germinativa dos diásporos de aroeira variou entre os tratamentos utilizados, com potencial germinativo e velocidade de germinação altos no tratamento-controle, indicando ausência de dormência. Nesse sentido, estudos básicos sobre as espécies florestais ameaçadas podem ser precursores de modelos e mecanismos para manejo e recuperação de suas populações naturais.
\end{abstract}

Palavras-chave: Ecofisiologia, conservação de espécies e ecologia de populações.

\section{ECOLOGICAL ASPECTS OF AROEIRA (Myracrodruon urundeuva ALLEMÃO - ANACARDIACEAE): PHENOLOGY AND SEED GERMINATION}

\begin{abstract}
Myracrodruon urundeuva Allemão, an arboreal species known as aroeira, is an important component of seasonal dry forests in northern Minas Gerais. In spite of that, aroeira is experiencing a process of predatory exploitation, causing the devastation of its natural populations. This study aimed to assess the reproductive and vegetative phenological patterns, and the germinating capacity of the species. The study was carried out at the COPASA Preservation Area in Juramento $(M G)$, where phenological phases were systematically observed bimonthly, from Janurary/2002 to November/2003 in 20 arboreal individuals. Seeds were collected and submitted to different scarification treatments (mechanic, thermal, chemical and control). The reproductive and vegetative phenophases of the species are influenced by environmental conditions. During the dry season, flowering, fructification and leaffall occur, whereas the wet season favors leaf growth. Besides, the germination of aroeira seeds varied among treatments, with higher germinating potential and germination velocity being verified in the control treatment, indicating the absence of dormancy. Therefore, basic studies on the ecology of threatened forest species are essential to generate models and mechanisms for the management and restoration of their natural populations.
\end{abstract}

Keywords: Arboreal species, deciduous dry forest and eco-physiology.

\footnotetext{
${ }^{1}$ Recebido em 23.02.2007 e aceito para publicação em 20.02.2008.

${ }^{2}$ Departamento de Biologia Geral da Universidade Estadual de Montes Claros, CP 126, 39401-089 Montes Claros-MG. E-mail :<yule.nunes@unimontes.br>.

${ }^{3}$ Programa de Pós-Graduação em Engenharia Florestal da Universidade Federal de Lavras, 37200-000 Lavras-MG.
} 


\section{INTRODUÇÃO}

Myracrodruon urundeuva Allemão (Anacardiaceae), conhecida popularmente como aroeira, aroeira-dosertão ou urundeúva, é uma espécie decídua, heliófita e seletiva xerófita (LORENZI, 1992). Seu limite de distribuição natural se estende pelas Regiões Nordeste, Sudeste e Centro-Oeste do Brasil até a região chaquenha da Bolívia, Paraguai e Argentina (SANTIN e LEITÃO-FILHO, 1991; LORENZI, 1992; CARVALHO, 1994; GURGEL-GARRIDO et al., 1997). Nas Florestas Estacionais Deciduais do norte de Minas Gerais, a aroeira ocorre freqüentemente nas matas secas calcárias e na caatinga arbórea (BRANDÃO, 1994; SANTOS et al., 2007).

O porte da aroeira varia conforme a região de sua ocorrência (LORENZI, 1992; ANDRADE et al., 2000), podendo atingir $30 \mathrm{~m}$ de altura (RIZZINI, 1971). Geralmente, a espécie floresce entre julho e setembro, e a maturação dos frutos ocorre de setembro a outubro (LORENZI, 1992; ANDRADE et al., 2000). A polinização de $M$. urundeuva é realizada por abelhas, e a dispersão dos diásporos é anemocórica. Seus frutos são do tipo drupa globosa ou ovóide, com cálice persistente, considerado um fruto-semente (FIGUEIRÔA et al., 2004). A semente é única ( 0,2 a 0,4 cm de diâmetro), globosa, desprovida de endosperma, com epicarpo castanhoescuro, mesocarpo castanho, carnoso, resinífero, com odor característico e tegumento membranáceo (MEDEIROS, 1996; ALMEIDA et al., 1998).

A aroeira apresenta grande uso farmacológico. Sua entrecasca possui propriedades antiinflamatórias, adstringentes, antialérgicas e cicatrizantes (VIANA et al., 1995). As raízes são usadas no tratamento de reumatismo e as folhas são indicadas para o tratamento de úlceras (ALMEIDA et al., 1998). Além disso, sua madeira, em função da durabilidade e dificuldade de putrefação, é muito usada na construção civil como postes ou dormentes para cercas, na confecção de móveis de luxo e adornos torneados (ALMEIDA et al., 1998; LORENZI, 1992). No entanto, devido aos seus princípios alergênicos, a árvore não deve ser cultivada em locais de fácil acesso ao público (ALMEIDA et al., 1998).

Em decorrência desses múltiplos usos, a aroeira vem sofrendo um processo de exploração intensa, de forma predatória, causando a devastação de suas populações naturais. Além disso, deve-se salientar que a exploração seletiva da aroeira para uso na indústria madeireira praticamente extinguiu os indivíduos de grande porte (BRANDÃO, 2000), sendo, portanto, considerada ameaçada de extinção e categorizada como vulnerável (MENDONÇA e LINS, 2000). Assim, estudos ecológicos básicos, principalmente relacionados com a fenologia e germinação das sementes de M. urundeuva, são essenciais para programas de preservação, manejo e restauração de suas populações.

A fenologia descreve eventos biológicos repetitivos, em nível de população ou comunidade, procurando relacionar esses eventos com fatores bióticos e abióticos (FERRAZ et al., 1999). Assim, a precipitação, a temperatura, o fotoperíodo, a intensidade de radiação, a qualidade do solo e a presença ou ausência de animais dispersores e predadores de frutos/sementes encontramse relacionados com as épocas de floração, frutificação, queda e brotamento de folhas (PEDRONI et al., 2002). Desse modo, estudos que visam à caracterização das fenofases vegetais são importantes para a compreensão da dinâmica das populações de plantas (SPINA et al., 2001), funcionando como indicadores das respostas das plantas às condições climáticas e edáficas locais (FOURNIER, 1974).

Entre os diferentes estágios do ciclo de vida dos vegetais superiores, a germinação das sementes é um dos pontos mais críticos para o sucesso das plantas (METIVIER, 1986). A germinação, do ponto de vista fisiológico, pode ser dividida em diferentes etapas: embebição de água (reidratação), aumento da respiração, alongamento das células, divisão celular (consequiente formação de enzimas, digestão, mobilização e transporte das reservas e assimilação metabólica), crescimento e diferenciação dos tecidos (CASTRO e HILHORST, 2004). Fatores bióticos, intrínsecos à própria semente, e abióticos, como luz, temperatura e umidade, afetam diferentemente a germinação (BASKIN e BASKIN, 1998). Além disso, muitos diásporos apresentam algum mecanismo de dormência que dificulta sua propagação. Assim, trabalhos têm sido desenvolvidos com o objetivo de quebrar a dormência das sementes, aumentando a taxa germinativa dos propágulos para a produção de mudas (ZAIDAN e BARBEDO, 2004).

Nos próximos 30-40 anos, cerca de 25\% das espécies vegetais do planeta poderão entrar em perigo de extinção (FERNANDES, 2002). A aroeira, apesar de amplamente distribuída, está ameaçada de extinção (MENDONÇA 
e LINS, 2000). Desse modo, este trabalho teve como objetivo conhecer os padrões fenológicos reprodutivos e vegetativos e a capacidade germinativa de $M$. urundeuva, com o intuido de fornecer informações para o desenvolvimento dos programas de recuperação de suas populações naturais, através do conhecimento da melhor época de coleta de sementes na região e da maximização da produção de mudas.

\section{MATERIAL E MÉTODOS}

\section{1. Área de estudo}

Este estudo foi desenvolvido na Área Preservação da Companhia de Saneamento de Minas Gerais COPASA S.A., em Juramento, Norte de Minas Gerais (1646'20’'S e 4339'56”W). Essa Área de Preservação possui um reservatório de $7,63 \mathrm{~km}^{2}$ de área inundada, sendo formado pelo represamento dos rios Juramento, Saracura e Canoas. No entorno da represa, uma área de $23,37 \mathrm{~km}^{2}$ foi mantida preservada desde a implantação do empreendimento em 1986 (NUNES et al., 2005).

O clima da região é do tipo semi-árido, com duas estações bem definidas, sendo uma chuvosa (de outubro a março) e uma estação seca (de abril a setembro). A temperatura média oscila em torno $23^{\circ} \mathrm{C}$ e a precipitação anual, ao redor de $1.000 \mathrm{~mm} / \mathrm{ano}$, com chuvas concentradas nos meses de novembro a janeiro. Fisionomicamente, a área de estudo se encontra na transição dos Domínios do Cerrado e da Caatinga, apresentando como principais fisionomias a mata seca (Floresta Estacional Decidual), que é predominante na área, e o Cerrado sentido restrito (NUNES et al., 2005).

\subsection{Registro dos dados fenológicos}

Para o acompanhamento fenológico de $M$. urundeuva, 20 indivíduos arbóreos foram selecionados, marcados e monitorados quinzenalmente, durante 23 meses. Esses indivíduos possuíam troncos aproximadamente retilíneos, copas abundantes e boas condições fitossanitárias (ausência aparente de doenças e infestações de parasitas). As árvores marcadas apresentavam CAP (circunferência à altura do peito mensurada a $1,30 \mathrm{~m}$ do solo) superior a $20 \mathrm{~cm}$ e altura acima de $3 \mathrm{~m}$. Placas de alumínio numeradas foram usadas para a identificação das plantas no campo.

Os registros dos dados fenológicos foram realizados entre a primeira quinzena de janeiro de 2002 e a primeira quinzena de novembro de 2003, totalizando 45 observações. Durante esse período de monitoramento foram registradas seis fenofases: (1) botões florais, caracterizada desde o início da formação da estrutura floral até a abertura dos botões florais; (2) antese, representada pela abertura dos botões florais até a queda das peças florais; (3) frutos imaturos, fase desde a formação do fruto até o amadurecimento, visualizada pela presença de frutos de coloração verde; (4) frutos maduros, representada pela presença de frutos com coloração beje-creme; (5) queda de folhas, caracterizada pela presença de folhas amarelas na copa, perda das folhas sob o vento e presença de folhas caídas sob a copa das árvores; e (6) brotamento, marcada pelo aparecimento de pequenas folhas com coloração diferenciada (avermelhada). A ocorrência de deciduidade completa também foi registrada.

Para a quantificação dos eventos fenológicos, foram usados o índice de atividade e o índice de intensidade de Fournier (1974). O índice de atividade refere-se à porcentagem de indivíduos manifestando o evento em cada amostragem, quando é registrada somente a presença ou ausência da fenofase específica. Esse método também estima a sincronia entre os indivíduos da população (FERRAZ et al., 1999; PEDRONI et al., 2002). Para a determinação do índice de intensidade de Fournier, foram obtidos dados fenológicos em campo, através de uma escala intervalar semiquantitativa de cinco categorias (0 a 4), com intervalo de $25 \%$ entre cada categoria. Quinzenalmente, os valores obtidos de todos os indivíduos foram somados e divididos pelo valor máximo possível (número de indivíduos multiplicado por quatro). Esse valor corresponde a uma proporção que é, então, multiplicada por 100, para transformá-la em um valor porcentual (D`EÇA-NEVES e MORELLATO, 2004).

Posteriormente, os dados fenológicos de intensidade e atividade de cada fenofase foram relacionados com a precipitação e temperatura média quinzenais, no período de estudo, através da correlação de Spearman (ZAR, 1996), e descritivamente com as normais climatológicas da área (Figura 1A). Os dados climatológicos foram obtidos quinzenalmente (janeiro/2002 a novembro/2003), na Estação Climatológica da COPASA, localizada na área de estudo (Figura 1B). Dados climáticos dessa Estação também foram computados no período de 1987 (ano de sua instalação) a 2002, para caracterização das normais climáticas da região.

R. Árvore, Viçosa-MG, v.32, n.2, p.233-243, 2008 

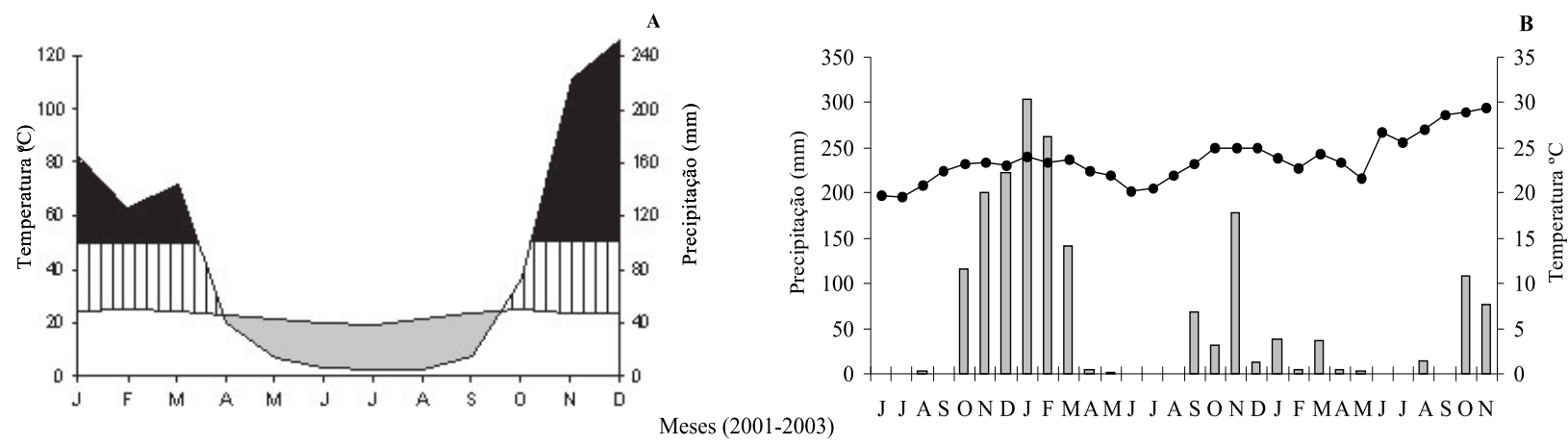

Figura 1 - Caracterização climática da área de estudo obtida na Estação Climatológica da COPASA - Juramento, MG: (A) normais climatológicas (1987-2002) e (B) precipitação total e temperaturas médias mensais nos anos de 20012003.

Figure 1 - Climatic characterization of the study area obtained at the Climatologic Station of COPASA - Juramento, MG: (A) climatologic normal (1987-2002) and (B) total rainfall and month mean temperatures from 2001 to 2003.

\subsection{Germinação das sementes}

Os diásporos de aroeira utilizados no teste de germinação foram coletados em 20 árvores-matriz localizadas na área de estudo, em setembro de 2001. Após a coleta, os frutos/sementes permaneceram armazenados por 15 dias, em sacos de papel. Os testes de germinação foram realizados em placas de Petri, onde os diásporos foram distribuídos homogeneamente em papel-filtro sobre uma espuma de $1 \mathrm{~cm}$ de espessura. Cada amostra foi regada com $20 \mathrm{~mL}$ de água destilada, e todo material utilizado no experimento foi esterilizado e limpo previamente, utilizando-se detergente e, ou, hipoclorito de sódio (2\%).

Foi utilizado um delineamento experimental inteiramente casualizado com quatro tratamentos e 10 repetições por tratamento. A unidade experimental foi representada por uma placa de Petri com 25 sementes. Os tratamentos utilizados constaram de sementes intactas (controle) e sementes escarificadas com ácido sulfúrico (durante $5 \mathrm{~min}$ ), com água quente e lixa de acabamento $\left(n^{\circ} 80\right)$. As sementes do tratamento de escarificação térmica foram colocadas em água quente a $70^{\circ} \mathrm{C}$ e permaneceram nessas condições até a temperatura atingir $50^{\circ} \mathrm{C}$ (em torno de $30 \mathrm{~min}$ ). O experimento foi acompanhado diariamente, em horário fixo, durante 30 dias, quando se considerou germinada a semente cuja radícula havia emergido(BORGHETTIeFERREIRA, 2004). Os experimentos foram conduzidos em germinador com temperatura e luz alternadas $\left(30^{\circ} \mathrm{C}\right.$ luz/12 h: $20^{\circ} \mathrm{C}$ escuro/12 h).

Os efeitos dos diferentes tratamentos na germinação das sementes foram avaliados através da Análise de Variância (ANOVA). A porcentagem de germinação foi transformada para a função arco-seno da raiz quadrada da porcentagem para normalização dos dados (ZAR, 1996). As análises foram realizadas no sistema estatístico R (R DEVELOPMENT... 2007).

\section{RESULTADOS}

\subsection{Fenologia}

Variações na temperatura e na precipitação afetaram igualmente os índices de atividade e de intensidade de cada fenofase de $M$. urundeuva (Quadro 1). A produção de botões florais e a abertura das flores (antese) correlacionaram-se negativamente com a precipitação. De fato, esses eventos fenológicos concentraram-se nos meses de menor precipitação (julho a agosto) nos dois anos de estudo, com picos de $100 \%$ de atividade e $71 \%$ de intensidade de botões florais e $100 \%$ de atividade e $64 \%$ de intensidade de flores abertas em 2002 e 2003, respectivamente (Figura 2A).

A ocorrência de frutos imaturos na aroeira correlacionou-se negativamente com a precipitação e positivamente com a temperatura (Quadro 1). Assim, frutos imaturos foram observados de julho a setembro/ 2002 e julho a agosto/2003, com picos em agosto/2002 e julho/2003 (Figura 2B). Entretanto, apenas a temperatura afetou a ocorrência de frutos maduros. De modo geral, a maturação dos frutos da aroeira ocorreu entre agosto e novembro, período que coincide com a elevação da temperatura ambiental. Assim, pode-se dizer que a produção de frutos pela aroeira concentra-se no período frio e seco, enquanto a maturação desses frutos é dependente da elevação da temperatura. 
Quadro 1 - Correlação de Spearman entre os índices de atividade e de intensidade quinzenais das diferentes fases fenológicas de Myracrodruon urundeuva (aroeira) e as variáveis climáticas no período de janeiro/2002 a novembro/2003, na área de preservação da COPASA - Juramento, MG: $\mathrm{r}=$ correlação de Spearman, $\mathrm{p}=$ probabilidade e $\mathrm{n}=$ amostras

Table 1 - Sperman correlation among bimonthly activity and intensity indices of different phenological phases of Myracrodruon urundeuva (aroeira) and climatic conditions from January/2002 to November/2003, at COPASA Preservation Area - Juramento $(M G) . r=$ Spearman correlation; $p=$ probability; $n=$ samples

\begin{tabular}{lccccc}
\hline Fenofase & Avaliação & Variável Climática & $\mathrm{r}$ & P & $\mathrm{n}$ \\
\hline Botões Florais & Atividade & Precipitação & $-0,566$ & $0,000^{*}$ & 45 \\
& & Temperatura & $-0,018$ & 0,907 & 45 \\
& Intensidade & Precipitação & $-0,630$ & $0,000^{*}$ & 45 \\
Antese & & Temperatura & $-1,102$ & 0,506 & 45 \\
& Atividade & Precipitação & $-0,481$ & $0,001^{*}$ & 45 \\
& & Temperatura & 0,175 & 0,249 & 45 \\
Frutos Imaturos & Intensidade & Precipitação & $-0,477$ & $0,001^{*}$ & 45 \\
& & Temperatura & 0,168 & 0,269 & 45 \\
& Atividade & Precipitação & $-0,319$ & $0,033^{*}$ & 45 \\
Frutos Maduros & & Temperatura & 0,311 & $0,038^{*}$ & 45 \\
& Intensidade & Precipitação & $-0,319$ & $0,033^{*}$ & 45 \\
& & Temperatura & 0,312 & $0,037 *$ & 45 \\
Queda de folhas & Atividade & Precipitação & $-0,085$ & 0,578 & 45 \\
& & Temperatura & 0,551 & $0,000^{*}$ & 45 \\
& Intensidade & Precipitação & $-0,116$ & 0,446 & 45 \\
& & Temperatura & 0,535 & $0,000^{*}$ & 45 \\
Brotamento & Atividade & Precipitação & $-0,593$ & $0,000^{*}$ & 45 \\
& & Temperatura & $-0,359$ & $0,015 *$ & 45 \\
& Intensidade & Precipitação & $-0,632$ & $0,000^{*}$ & 45 \\
& & Temperatura & $-0,330$ & $0,027 *$ & 45 \\
& Atividade & Precipitação & 0,576 & $0,000^{*}$
\end{tabular}

* Valores significativos a $5 \%$ de probabilidade

A precipitação e a temperatura afetaram negativamente a queda foliar, enquanto a precipitação afetou positivamente a produção de folhas pela aroeira. Esses resultados indicam que a queda de folhas aumentou com a diminuição da precipitação e da temperatura, e o brotamento aumentou com o incremento da precipitação. Assim, os períodos de fevereiro a outubro/ 2002 e de abril a outubro/2003 apresentaram maior atividade e intensidade de perda foliar (Figura 2C). Picos de queda foliar ocorreram em abril/2002 (95\% de atividade), julho/2002 (83\% de intensidade) e maio/ 2003 ( $100 \%$ de atividade e $76 \%$ de intensidade). Além disso, a deciduidade completa foi observada principalmente em junho/2002 e agosto/2003, em 86\% e $95 \%$ dos indivíduos, respectivamente (Figura 2D). A produção de folhas pela aroeira é interrompida nos meses de menor precipitação (abril a agosto), podendo destacar picos de atividade em novembro/2002 (80\%), fevereiro/2003 (80\%) e novembro/2003 (95\%) e de intensidade em novembro/2003 (80\%) (Figura 2C).

\subsection{Germinação de sementes}

A germinação das sementes de $M$. urundeuva variou entre os tratamentos $(\mathrm{gl}=3 ; \mathrm{F}=13,37$, $\mathrm{p}<0,001$; $\mathrm{n}$ =10). De fato, a escarificação com ácido sulfúrico reduziu a viabilidade das sementes em aproximadamente $50 \%$, em comparação com os demais tratamentos (Figura 3A). Observou-se também que as sementes dos tratamentos-controle e escarificações mecânica e térmica apresentaram maiores taxas de germinação entre o segundo e o terceiro dia de incubação. No entanto, as sementes escarificadas com ácido sulfúrico exibiram maiores taxas de geminação entre o terceiro e o quarto dia de incubação (Figura 3B).

R. Árvore, Viçosa-MG, v.32, n.2, p.233-243, 2008 

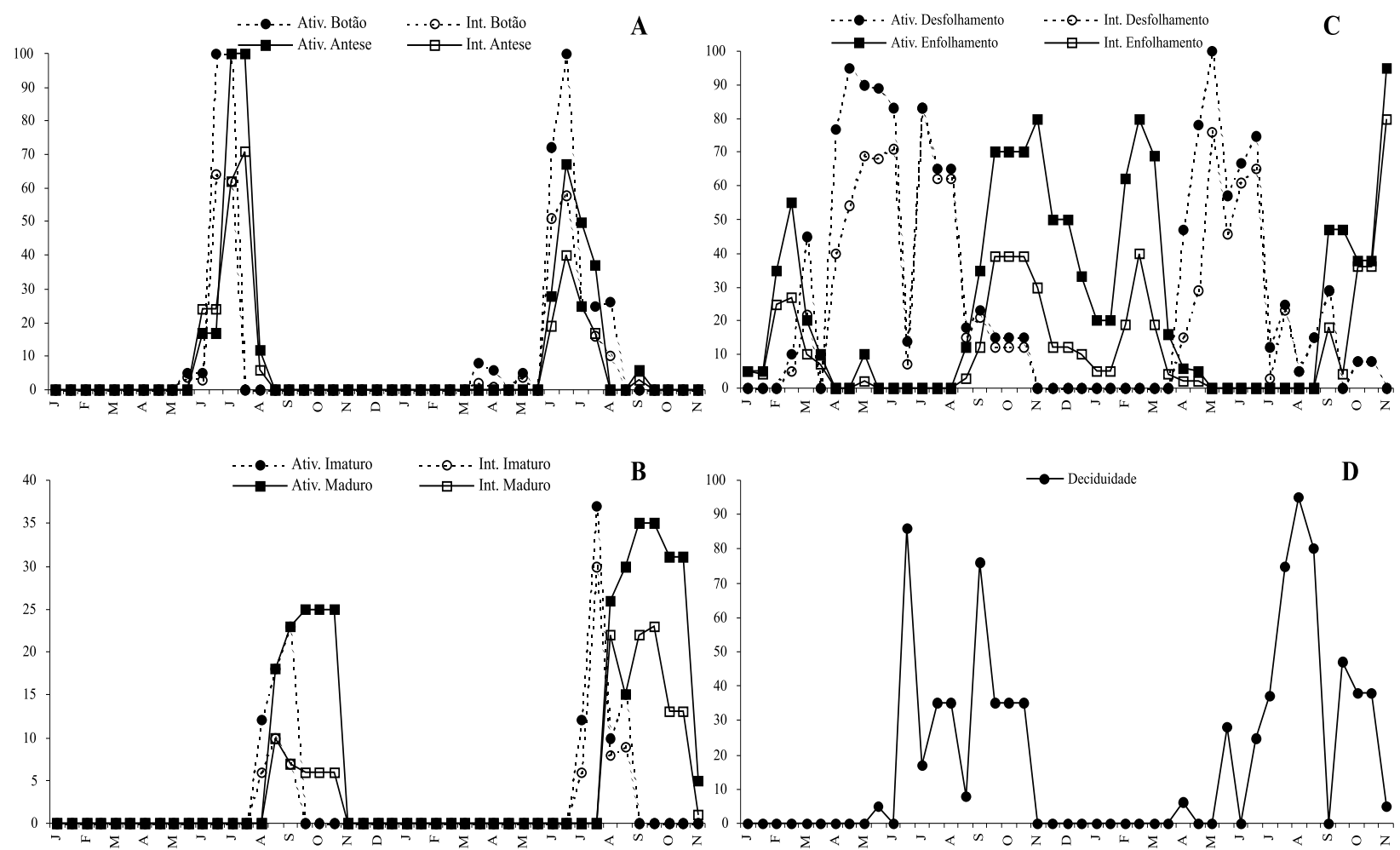

B
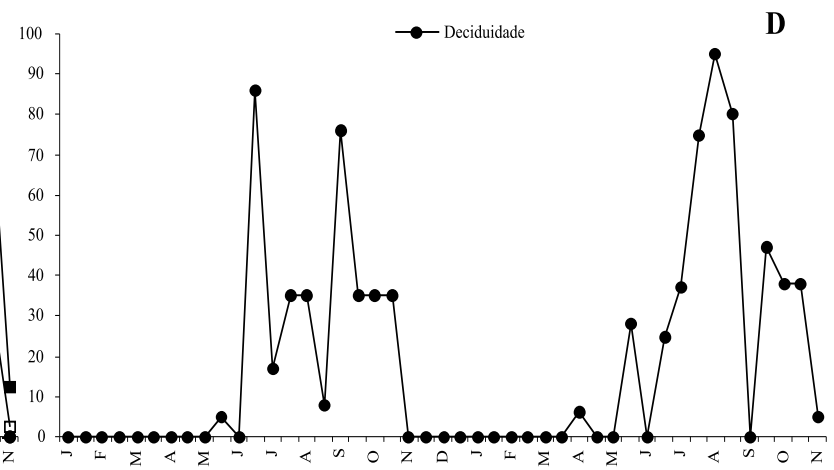

Figura 2 - Índices de atividade e intensidade fenológica de indivíduos de Myracrodruon urundeuva (aroeira) na área de preservação da COPASA - Juramento, MG, durante o período de janeiro/2002 a novembro/2003: (A) Floração - botões florais e antese, (B) frutificação - frutos imaturos e frutos maduros, (C) brotamento e queda de folhas e (D) indivíduos com caducifolia completa.

Figure 2 - Indices of phenological activity and intensity of Myracrodruon urundeuva (aroeira) individuals at COPASA Preservation Area-Juramento $(M G)$, from January/2002 to November/2003. (A) Flowering - flower buds and flowering; (B) fructification - immature fruit and mature fruit; $(C)$ leafflushing and leaffall; and $(D)$ individuals with complete leaffall.
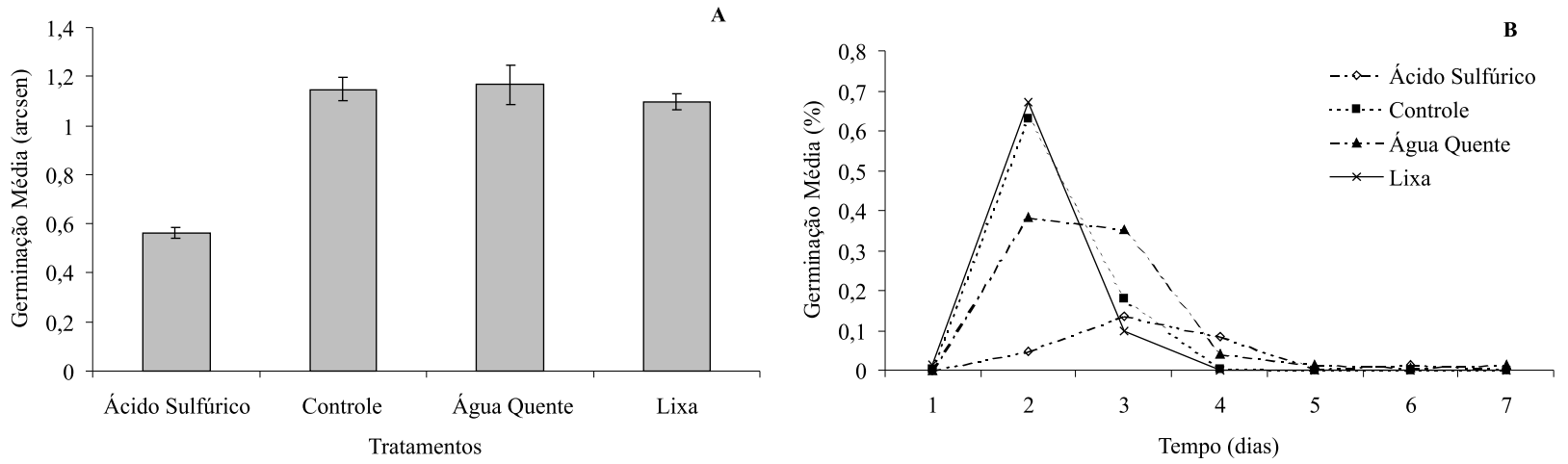

Figura 3 - (A) Germinação total (arco-seno £ erro-padrão) e (B) porcentagem média diária de germinação de sementes de Myracrodruon urundeuva (aroeira) submetidas a diferentes tratamentos de escarificação.

Figure $3-(A)$ Total germination (arcosen \pm standart error) and $(B)$ daily mean percent of germination of Myracrodruon urundeuva (aroeira) seeds submitted to different scarification treatments.

R. Árvore, Viçosa-MG, v.32, n.2, p.233-243, 2008 
O comportamento germinativo das sementes também variou entre os tratamentos (Quadro 2). As sementes dos tratamentos-controle e lixa germinaram do primeiro até o terceiro e quarto dias de incubação, respectivamente. No entanto, as sementes escarificadas química e termicamente germinaram do segundo ao sétimo dia. Assim, nota-se que as sementes do grupo-controle apresentaram melhor performance germinativa (altas taxa de germinação e regularidade temporal). Tais resultados indicam que os diásporos da aroeira não apresentam dormência tegumentar e, portanto, não necessitam de tratamentos de escarificação para acelerar e, ou, aumentar seu potencial germinativo.

\section{DISCUSSÃO}

\subsection{Fenologia}

O crescimento vegetativo e reprodutivo da maioria das árvores tropicais é freqüentemente limitado a curtos períodos do ano (TERBORGH, 1992). Myracrodruon urundeuva apresentou um período de crescimento (brotamento) relativamente amplo, contudo a fase reprodutiva foi reduzida. Por exemplo, a floração (botões florais e antese) teve curta duração (dois meses) e foi ainda restrita ao período de déficit hídrico. Além disso, foram observados altos índices de sincronismo (atividade) e produtividade (intensidade) reprodutiva dos indivíduos nesse período. Fatores ambientais, especialmente a precipitação, afetam a atividade de agentes polinizadores, e as espécies vegetais, através de mecanismos de resposta aos estímulos ambientais, estão sincronizadas com os agentes bióticos (MANTOVANI e MARTINS, 1988). Além disso, a produção de inflorescências no período de déficit hídrico encontra-se associada a uma maior proteção aos órgãos reprodutivos (PEDRONI et al., 2002). Na região de estudo, as chuvas intensas ocorrem especialmente entre dezembro e janeiro. Assim, é provável que a concentração da floração de $M$. urundeuva em um período restrito do ano represente uma adaptação da planta a fatores abióticos e bióticos locais, conforme sugerido por Nunes et al. (2005) para Guazuma ulmifolia (Malvaceae).

A frutificação das árvores responde a estímulos ambientais como fotoperíodo, precipitação e temperatura e a fatores bióticos como polinizadores e dispersores de frutos/ sementes (SPINA et al., 2001). Esses fatores afetam a formação dos frutos, a dispersão, a germinação das sementes e o estabelecimento dos indivíduos (ANTUNES e RIBEIRO, 1999). Na aroeira, os frutos imaturos têm ocorrência mais limitada temporalmente do que os frutos maduros. Na região de estudo, esta época se caracteriza pela baixa precipitação e ocorrência de ventos intensos. Assim, os frutos desenvolvemse em um clima propício à dispersão de seus propágulos anemocóricos e antes da estação chuvosa, facilitando uma posterior germinação das sementes e estabelecimento das plântulas no início da estação úmida (MORELLATO, 1992; NUNES et al., 2005).

Quadro 2 - Porcentagem média de germinação, número médio de sementes germinadas, pico de germinação (dia e porcentagem média) e tempo de germinação de sementes de Myracrodruon urundeuva (aroeira), submetidas a diferentes tratamentos de escarificação durante 30 dias no germinador

Table 2 - Germination mean percentage, mean number of germinated seeds, germination peak (day and mean percentage) and germination time of Myracrodruon urundeuva (aroeira) seeds, at different scarification treatments during 30 days of incubation

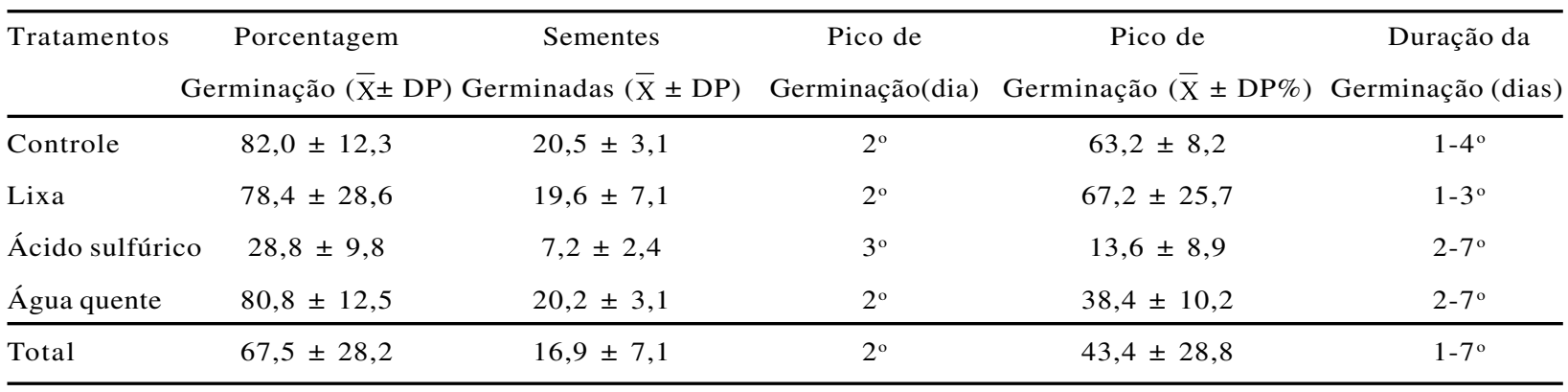

R. Árvore, Viçosa-MG, v.32, n.2, p.233-243, 2008 
A queda foliar também apresentou relações marcantes com o período seco do ano, mostrando ainda elevada porcentagem de deciduidade completa dos indivíduos nesse período. Conforme Morellato (1992), no início da estação seca ocorre maior retirada de nutrientes do solo pelo aumento da evapotranspiração, sendo ao final dessa estação a absorção de nutrientes dificultada pela baixa umidade do ar e a diminuição da disponibilidade de água no solo, ocasionando, assim, a perda das folhas da maioria das espécies. Desse modo, a perda de folhas no período seco constitui um fator de economia hídrica para as plantas, e os baixos índices de umidade estimulam a abscisão foliar (BORCHERT et al., 2002). Dessa forma, a acentuada sazonalidade das chuvas na região, concentradas em apenas quatro meses, favorece a intensa queda de folhas dos indivíduos no período de seca. Além disso, é provável que durante a estação seca ocorra um desvio de recursos da fase vegetativa para a fase reprodutiva, uma vez que a espécie investe na produção de flores e na formação dos frutos durante o período de intensa senescência foliar (FOSTER, 1990).

O brotamento das espécies em florestas sazonais parece ser influenciado principalmente pela disponibilidade de água e luz (BORCHERT, 1994). De fato, o brotamento de $M$. urundeuva aumentou com o incremento da precipitação. Apesar disso, somente no período de junho a agosto, em ambos os anos de estudo, a aroeira não emitiu folhas novas, sendo um evento constante em quase todo o ano. Ademais, outros fatores ambientais, como o comprimento do dia, podem ser determinantes da fenologia foliar (MARQUES e OLIVEIRA, 2004).

\subsection{Germinação das sementes}

A germinação das sementes é determinada principalmente pela absorção de água, ressaltandose que a velocidade desse processo depende da permeabilidade do tegumento, temperatura e composição química da semente (SOUSA-SILVA et al., 2001). As sementes da aroeira não apresentam dormência física. De fato, as sementes não escarificadas (controle) apresentaram germinabilidade idêntica à daquelas submetidas aos tratamentos de escarificação mecânica ou térmica. Além disso, esses tratamentos resultaram em altas taxas de germinação (78 a 82\%), comparativamente com outros estudos (DORNELES et al., 2005) que indicam que a taxa de germinação das sementes da aroeira varia de 20 a $90 \%$, com valores abaixo de $70 \%$ de germinação sendo os mais freqüentes.

Além das porcentagens de germinação, que oferecem informações sobre as características de germinação do conjunto de sementes submetidas a determinado tratamento, a velocidade de germinação permite interpretações adicionais (BORGHETTI e FERREIRA, 2004). Neste estudo, apesar de a porcentagem média total de germinação não ter variado entre os tratamentoscontrole, lixa e água quente, as sementes escarificadas termicamente apresentaram velocidade de germinação menor e, conseqüentemente, demandaram tempo de incubação maior. Assim, conforme o tratamento recebido, uma mesma espécie pode apresentar diferentes padrões de distribuição temporal da germinação (BORGHETTI e FERREIRA, 2004). Além disso, sementes intactas apresentaram velocidade de germinação semelhante àquelas lixadas, denotando, mais uma vez, a ausência de dormência tegumentar nas sementes de aroeira.

Entre todos os tratamentos utilizados neste estudo, as sementes escarificadas quimicamente apresentaram a menor porcentagem média de germinação. De fato, sementes que apresentem tegumento duro podem ter sua dormência quebrada pelo ácido sulfúrico (ZAIDAN e BARBEDO, 2004). Entretanto, as sementes de $M$. urundeuva exibem tegumento membranáceo e são desprovidas de endosperma (MEDEIROS, 1996). Desse modo, o uso do agente químico pode ter ocasionado danos ao embrião, impedindo a germinação de muitas sementes.

Apesar do aumento do interesse pelo estudo sobre a propagação das espécies florestais nativas, principalmente devido à necessidade da recuperação da paisagem e das populações naturais, existem poucos dados disponíveis para a maioria das espécies (ARAÚJONETO et al., 2003), inclusive sobre M. urundeuva (MEDEIROS, 1996; SILVA et al., 2002; FIGUEIRÔA et al., 2004; DORNELES et al., 2005; PACHECO et al., 2006). Assim, é necessário aumentar o conhecimento básico da germinação e propagação dessas espécies, principalmente da aroeira, cuja ocorrência, utilidade e vulnerabilidade elevam sua importância.

\section{CONCLUSÃO}

Myracrodruon urundeuva, na Área de Preservação da COPAS A-Juramento, MG, apresentou relações marcantes com as variáveis ambientais, demonstrando, 
com isso, relações ecológicas intrincadas com esse ambiente de sazonalidade acentuada. Além do mais, a coleta de propágulos dessa espécie na região pode ser realizada entre agosto e novembro, não havendo necessidade de tratamento de escarificações tegumentares, uma vez que se observou ausência de dormência física.

\section{AGRADECIMENTOS}

À FAPEMIG, pelo financiamento do projeto (DEG 2393/3) e pela concessão das bolsas BIC para H. S. Almeida e BIPDT para Y. R. F. Nunes e M. Fagundes; à COPASA, pelo apoio financeiro e logístico e pela permissão do desenvolvimento deste trabalho em sua Área de Preservação, em Juramento, MG; aos colegas G. C. Castro, M. Soares, M. V. Pacheco, R. L. Mendonça, R. M. Santos, E. B. S. Domingues, A. P. D. Gonzaga e M. R. Santos, pelo auxílio nos trabalhos de campo e laboratório; e aos revisores anônimos, pelas prestimosas sugestões e contribuições ao manuscrito deste trabalho.

\section{REFERÊNCIAS}

ALmeidA, S. P. et al. Cerrado: espécies vegetais úteis. Planaltina: Embrapa-CPAC, 1998. 188 p.

ANDRADE, M. W. et al. Micropropagação da aroeira (Myracrodruon urundeuva Fr. All.). Ciência e Agrotecnologia, v.24, n.1, p.174-180, 2000.

ANTUNES, N. B.; RIBEIRO, J. F. Aspectos fenológicos de seis espécies vegetais em Matas de Galeria do Distrito Federal. Pesquisa Agropecuária Brasileira, v.34, n.9, p.1517-1527, 1999.

ARAÚJO-NETO, J. C.; AGUIAR, I. B.; FERREIRA, V. M. Efeito da temperatura e da luz na germinação de sementes de Acacia polyphylla DC. Revista Brasileira de Botânica, v.26, n.2, p.249-256, 2003.

BASKIN, C. C.; BASKIN, J. M. Seeds: Ecology, biogeography, and evolution of dormancy and germination. London: Academic Press, 1998. 666p.

BORCHERT, R.; RIVERA, G.; HAGNAUER, W. Modification of vegetative phenology in a tropical semi-deciduous forest by abnormal drought and rain. Biotropica, v.34, n.1, p.27-39, 2002.
BORCHERT, R. Soil and stem water storage determine phenology and distribution of tropical dry forest trees. Ecology, v.75, n.5, p.1437-1449, 1994.

BORGHETTI, F.; FERREIRA, A. G. Interpretação de resultados de germinação. In: FERREIRA, A. G.; BORGHETTI, F. (Eds). Germinação: do básico ao aplicado. Porto Alegre: Artmed, 2004. p.209-222.

BRANDÃO, M. Área Mineira do Polígono das Secas / Cobertura Vegetal. Informe Agropecuário, v.17, n.181, p.5-9, 1994.

BRANDÃO, M. Caatinga. In: MENDONÇA, M. P.; LINS, L. V. (Orgs). Lista vermelha das espécies ameaçadas de extinção da flora de Minas Gerais. Belo Horizonte: Fundação Biodiversitas e Fundação Zôo-Botânica de Belo Horizonte, 2000. p.75-85.

CARVALHO, P. E. R. Espécies florestais brasileiras: recomendações silviculturais, potencialidades e uso da madeira. Brasília: Embrapa/CNPF, 1994. 640p.

CASTRO, R. D.; HILHORST, H. W. M. Embebição e reativação do metabolismo. In: BORGHETTI, F. Germinação: do básico ao aplicado. Porto Alegre: Artmed, 2004. p.149-162.

D’EÇA-NEVES, F. F.; MORELLATO, L. P. C. Métodos de amostragem e avaliação utilizados em estudos fenológicos de florestas tropicais. Acta Botanica Brasilica, v.18, n.1, p.99-108, 2004.

DORNELES, M. C.; RANAL, M. A.; SANTANA, D.G. Germinação de diásporos recém-colhidos de Myracrodruon urundeuva Allemão (Anacardiaceae) ocorrente no cerrado do Brasil Central. Revista Brasileira de Botânica, v.28, n.2, p.399-408, 2005.

FERNANDES, A. Biodiversidade da caatinga. In: ARAÚJO, E. L. et al. (Eds). Biodiversidade, conservação e uso sustentável da flora do Brasil. Recife: UFRPE/SBB, 2002. p.42-43.

FERRAZ, D. K. et al. Fenologia de árvores em fragmentos de mata em São Paulo, SP.

Revista Brasileira de Biologia, v.59, n.2, p.305-317, 1999.

R. Árvore, Viçosa-MG, v.32, n.2, p.233-243, 2008 
FIGUEIRÔA, J. M.; BARBOSA, D. C. A.; SIMABUKURO, E. A. Crescimento de plantas jovens de Myracrodruon urundeuva Allemão (Anacardiaceae) sob diferentes regimes hídricos. Acta Botanica Brasilica, v. 18, n.3, p.573-580. 2004.

FOSTER, R. B. Ciclo estacional de caída de frutos en la isla de Barro Colorado. In: LEIGHT, E. G.; RAND, A. S.; WINDSOR, D. M. (Eds). Ecologia de um bosque tropical: ciclos estacionales y cambios a largo prazo. Balboa: Smithsonian Institution, 1990. p.219-241.

FOURNIER, L. A. Un metodo cuantitativo para la medición de características fenológicas en arboles. Turrialba, v.24, n.4, p.422-423, 1974.

GURGEL-GARRIDO, L. M. A. et al. Efeitos do sombreamento no crescimento da aroeira Myracrodruon urundeuva Fr. All. Revista do Instituto Florestal, v.9, p.47-56, 1997.

LORENZI, H. Árvores brasileiras: manual de identificação e cultivo de plantas arbóreas nativas do Brasil. São Paulo: Plantarum, 1992. v.1.368p.

MANTOVANI, W.; MARTINS, F. R. Variáveis fenológicas das espécies do cerrado da Reserva Biológica de Moji Guaçu, Estado de São Paulo. Revista Brasileira de Botânica, v.11, n.1/2, p.101-112, 1988 .

MARQUES, M. C. M.; OLIVEIRA, P. E. A. M. Fenologia de espécies do dossel e do sub-dossel de duas Florestas de Restinga na Ilha do Mel, Sul do Brasil. Revista Brasileira de Botânica, v.27, n.4, p.713-723, 2004.

\section{MEDEIROS, A. C. S. Comportamento}

fisiológico, conservação de germoplasma a longo prazo e previsão de longevidade de sementes de aroeira (Astronium urundeuva (Fr. All.) Engl.). 1996. 127f. Tese (Doutorado em Agronomia) - Universidade Estadual de São Paulo, Jaboticabal, 1996.

MENDONÇA, M. P.; LINS, L. V. (Orgs.). Lista vermelha das espécies ameaçadas de extinção da flora de Minas Gerais. Belo Horizonte: Fundação Biodiversitas, 2000. 157p.

R. Árvore, Viçosa-MG, v.32, n.2, p.233-243, 2008
METIVIER, J. R. Dormência e germinação. In: FERRI, M. G. (Coord). Fisiologia vegetal. 2.ed. São Paulo: EPU, 1986. p.343-392.

MORELLATO, L. P. C. Sazonalidade e dinâmica de ecossistemas florestais de uma área florestal no sudeste do Brasil. In: MORELLATO, L. P. C. (Org). História natural da Serra do Japi: ecologia e preservação de uma área florestal no sudeste do Brasil. Campinas: Universidade de Campinas, 1992. p.98-110.

NUNES, Y. R. F. et al. Atividades fenológicas em Guazuma ulmifolia Lam. (Malvaceae) em uma floresta estacional decidual no norte de Minas Gerais. Lundiana, v.6, n.2, p.99-105, 2005.

PACHECO, M. V. et al. Efeito de temperaturas e substratos na germinação de sementes de Myracrodruon urundeuva Fr. All. (Anacardiaceae). Revista Árvore, v.30, n.3, p.359-367, 2006.

PEDRONI, F.; SANCHEZ, M.; SANTOS, F. A. M. Fenologia da copaíba (Copaifera langsdorffii Desf. - Leguminosae, Caesalpinioideae) em uma floresta semidecídua no sudeste do Brasil.

Revista Brasileira de Botânica, v.25, n.2, p.183-194, 2002.

R DEVELOPMENT CORE TEAM R: A language and environment for statistical computing. R. Foundation for Statistical Computing, Vienna. 2007. <http://www.R-project.org >.

RIZZINI, C. T. Árvores e madeiras úteis do Brasil. Manual de dendrologia brasileira. São Paulo: Edgard Blücher, 1971. p.296.

SANTIN, D. A.; LEITÃO FILHO, H. F. Restabelecimento e revisão taxonômica do gênero Myracrodruon Freire Allemão (Anacardiaceae).

Revista Brasileira de Botânica, v.14, n.2, p.133-145, 1991.

SANTOS, R. M. et al. Riqueza e similaridade florística de oito remanescentes florestais no Norte de Minas Gerais, Brasil. Revista Árvore, v.31, n.1, p.135-144, 2007.

SILVA, L. M. M.; RODRIGUES, T. J. D.; AGUIAR, I. B. Efeito da luz e da temperatura na germinação de sementes de aroeira (Myracrodruon urundeuva Allemão). Revista Árvore, v.26, n.6, p.691-697, 2002. 
SOUZA-SILVA, M.; FONTENELLE, J. C. R.;

MARTINS, R. P. Seasonal abundance and species composition of flower-visiting flies. Neotropical Entomology, v.30, n.3, p.351-359, 2001.

SPINA, A. P.; FERREIRA, W. M.; LEITÃO FILHO, H. F. Floração, frutificação e síndromes de dispersão de uma comunidade de floresta de brejo na região de Campinas (SP). Acta Botanica Brasilica, v.15, n.3, p.349-368, 2001.

TERBORGH, J. Diversity and the tropical rain forest. New York: Scientific American Library, 1992. 242p.
VIANA, G. S. B. et al. Aroeira-do-sertão: estudo botânico, farmacognóstico, químico e farmacológico. Fortaleza: Universidade Federal do Ceará, 1995. 164p.

ZAIDAN, L. B. P.; BARBEDO, C. J. Quebra de dormência em sementes. In: FERREIRA, A. G.; BORGHETTI, F. (Orgs). Germinação: do básico ao aplicado. Porto Alegre: Artmed, 2004. p.135-146.

ZAR, J. H. Biostatistical analysis. 3.ed. New Jersey: Prentice-Hall, 1996. 662p. 